\title{
Controle de invasão biológica por capim-anonni em margem viária mediante a introdução de gramíneas ${ }^{1}$
}

\author{
Renato Borges de Medeiros ${ }^{2}$, Nadilson Roberto Ferreira ${ }^{2}$
}

\author{
1 Financiado pelo CNPq, CAPES e Sindicato Rural de Rio Pardo, RS. \\ 2 Faculdade de Agronomia, UFRGS, Caixa Postal 15100, 90001-970, Porto Alegre, RS.
}

\begin{abstract}
RESUMO - Objetivou-se avaliar o controle da invasão biológica por Eragrostis plana Nees (capim-anonni) em margens de rodovia com a introdução de gramíneas concorrentes associada a práticas de preparo do solo e adubação. O delineamento experimental foi em blocos casualizados com parcelas subdivididas e três repetições. Nas parcelas, foram avaliadas duas práticas de preparo do solo: solo subsolado e gradeado com aplicação de calcário e fósforo; e solo apenas subsolado, e nas subparcelas, as espécies de gramíneas: capim-mombaça (Megathyrsus maximus (Jacq.) B. K. Simon \& S. W. L. Jacobs); capim-kazangula (Setaria sphacelata (Schumach.) Stapf \& C. E. Hubb. ex M. B. Moss); mistura de sementes de três gramíneas nativas, grama-de-forquilha (Paspalum notatum Alain ex Flüggé), macega-do-banhado (Paspalum regnelli Mez) e capim-das-roças (Paspalum urvillei Steud.); avaliadas em comparação a uma subparcela de exclusão (testemunha). Nos levantamentos florísticos, realizados em 8 de janeiro de 2005, e após o plantio, em 26 de janeiro e 25 de junho de 2006, observou-se alta riqueza florística, com 86 espécies botânicas distribuídas em 29 famílias e $21 \%$ de espécies exóticas. O solo subsolado, gradeado, corrigido e adubado, associado às introduções de $M$. maximus e S. kazungula, foram as alternativas que mais contribuíram para reduzir a cobertura de E. plana. As gramíneas nativas presentes na vegetação do acostamento, Paspalum plicatulum Mitchx, Piptochaetium montevidense (Spreng.) Parodi e a espécie nativa introduzida (Paspalum urvillei) têm potencial para controlar a invasão de E. plana.
\end{abstract}

Palavras-chave: espécies concorrentes, gramíneas nativas, invasão biológica, restauração ecológica, riqueza florística

\section{Control of biological invasion by South African lovegrass on a roadside by introducing grasses}

\begin{abstract}
The objective of this study was to control biological invasion by Eragrostis plana Nees (South African lovegrass) on a roadside by introducing competitor grasses associated with soil management and fertilization practices. The experimental design was a complete randomized block with split-plots parcels and three replications. In the parcels, it was evaluated two practices of soil treatments: subsoil tillage plus disc harrow tillage and application of limestone and phosphorous; and only subsoil tillage and, in the split-plots, the following grass species: Megathyrsus maximus (Jacq.) B. K. Simon \& S. W. L. Jacobs; Setaria sphacelata (Schumach.) Stapf \& C. E. Hubb.; seed mixture of three native grasses, Paspalum notatum Alain ex Flüggé, Paspalum regnelli Mez and Paspalum urvillei Steud.; evaluated by comparison to an exclusion subplot (control). In the floristic surveys, which were performed on January $8^{\text {th }} 2005$, and after planting, in January $26^{\text {th }}$ and June $25^{\text {th }}$, 2006, a high floristic richness was observed, with 86 botanical species distributed in 29 families and $21 \%$ of exotic species. The subsoil tillage plus disc harrow tillage, limestone and fertilization associated with the introduction of M. maximus or with $S$. sphacelata were the treatments which contributed most to reduce E. plana frequency. The native grasses present in the roadside vegetation Paspalum plicatulum Mitchx, Piptochaetium montevidense (Spreng.) Parodi and the introduced native species Paspalum urvillei have potential to control E. plana invasion.
\end{abstract}

Key Words: biological invasion, competing species, ecological restoration, floristic richness, native grasses

\section{Introdução}

As comunidades vegetais nas margens viárias estão sob constante perturbação antropogênica e apresentam-se na forma de mosaicos, configuração que influencia na sucessão vegetal das comunidades do entorno (Tivy, 1993).
As faixas de domínio das rodovias são segmentadas e classificadas em zonas: na primeira, a vegetação é composta por espécies herbáceas de baixo porte e a alta intensidade de distúrbio determina o surgimento de plantas debilitadas e tolerantes ao estresse. Na segunda zona, ocorre uma vegetação de transição mais complexa que varia conforme 
um gradiente decrescente de distúrbio. Na terceira zona, mais afastada da rodovia, a composição florística é muito semelhante àquela da paisagem natural dominante (Froman et al., 2002).

Comunidades vegetais degradadas pela ação de distúrbios, como as de acostamentos viários, perdem riqueza e biodiversidade tornando-se mais suscetíveis à invasão biológica. Havendo subutilização de recursos pela comunidade residente, aumentam as chances de estabelecimento de espécies oportunistas (Davis et al., 2000). A invasão da pastagem nativa do Rio Grande do Sul (RS) por Eragrostis plana Nees (capim-annoni) decorreu de um fenômeno semelhante, em que a vegetação degradada dos acostamentos, inicialmente invadida, serviu de "ponte" para invasão subsequente da pastagem nativa fragilizada pelo superpastejo (Medeiros \& Focht, 2007).

E. plana é uma gramínea cespitosa, perene de ciclo estival, originária da África, introduzida acidentalmente no Brasil na década de 1950 (Reis \& Coelho, 2000); sua expansão para outras regiões ocorreu pelo transporte de animais e fluxo de veículos (Lisboa et al., 2009). Em razão disso, tornou-se dominante nos acostamentos viários do estado, constituindo-se no principal foco dispersor da espécie (Medeiros \& Focht, 2007).

Em um programa de controle de espécies invasoras, é essencial prevenir a dispersão por meio da remoção de focos disseminadores (Medeiros et al., 2004), que podem ser controlados pelo manejo ecológico da vegetação do acostamento viário (Medeiros \& Focht, 2007).

Com este trabalho objetivou-se controlar a invasão biológica por E. plana na margem de uma rodovia mediante a introdução de gramíneas concorrentes associada a práticas de preparo do solo e adubação.

\section{Material e Métodos}

O experimento foi estabelecido em 7 de abril de 2005 em um acostamento viário municipal, dominado por Eragrostis plana Nees, situado próximo da sede da Fazenda São Lucas, km 197 da BR 290, na região ecoclimática da Depressão Central, no município de Rio Pardo, Rio Grande do Sul. De acordo com a classificação de Köppen, o clima da região é $C f a$, subtropical úmido com chuvas bem distribuídas durante o ano, com a temperatura do mês mais quente superior a $22^{\circ} \mathrm{C}$ e a do mês mais frio superior a $3^{\circ} \mathrm{C}$ (Moreno, 1961). A cobertura vegetal da região é caracteristicamente composta por campos mistos, vegetação típica de transição entre os campos grossos da região do planalto e os campos finos da região da Campanha. A estrutura da vegetação é formada por dois estratos, um inferior, dominado por espécies de hábito caulescentes e um superior, composto por gramíneas cespitosas (Boldrini, 1997). No entorno da área experimental, E. plana é a espécie cespitosa mais dominante (Carlotto et al., 2010). O solo é identificado com o Argissolo Vermelho Distrófico Latossólico - PVd4 (Streck et al., 2002).

O delineamento experimental foi em blocos casualizados com parcelas subdivididas e três repetições, em uma área de $576 \mathrm{~m}^{2}$ protegida por cerca de arame farpado. Foram seis parcelas de $6 \times 16 \mathrm{~m}$ subdivididas em 24 subparcelas de $6 \mathrm{~m} \times 4 \mathrm{~m}$, dispostas ao longo do acostamento viário. Nas parcelas foram avaliadas duas práticas de manejo do solo: 1) solo subsolado, gradeado e com aplicação de calcário e fósforo; 2) solo apenas subsolado. Nas subparcelas, avaliaram-se quatro sistemas de cobertura vegetal: 1) introdução de capim-mombaça (Megathyrsus maximus B. K. Simon \& S. W. L. Jacobs); e 2) capim-kazungula (Setaria sphacelata (Schumach.) Staf \& C. E. Hubb. ex M. B. Moss); 3) reintrodução da mistura de três espécies nativas: grama-de-forquilha (Paspalum notatum Flüggé), macega-do-banhado (Paspalum regnellii Mez) e capim-das-roças (Paspalum urvillei Steud.); e 4) exclusão (testemunha).

Foram realizados levantamentos florísticos em três quadros permanentes de $0,5 \mathrm{~m} \times 0,5 \mathrm{~m}$, alocados ao acaso em cada subparcela (Mueller-Dombois \& Ellenberg 1974): o primeiro antes da aplicação dos tratamentos, em 8 de janeiro de 2005; o segundo em 27 de janeiro de 2006; e o último em 25 de junho de 2006. As estimativas visuais de abundânciacobertura das espécies foram realizadas de acordo com o método de Braun-Blanquet (Braun-Blanquet, 1979), e convertidos para a escala de Van der Maarel (Van der Maarel, 1979) para fins de análise estatística. A identificação das espécies era feita no campo. As espécies não identificadas a campo eram herborizadas para posterior determinação, feita por meio de consultas a especialistas e a literatura especializada e por meio de comparações com exsicatas do herbário do Departamento de Ecologia da Universidade Federal do Rio Grande do Sul. Identificaram-se a origem e o nome vulgar das espécies exóticas encontradas nos levantamentos florísticos com base nos trabalhos de Irgang (1974), Marodin \& Baptista (2001) e Schneider \& Irgang (2005).

Os dados fitossociológicos de cobertura relativa foram sintetizados com auxílio do Aplicativo Excel. A partir dos valores relativos, calculou-se o índice de valor de importância de cada espécie, que, numericamente, indica a posição de cada uma no ecossistema estudado (Mueller-Dombois \& Ellenberg, 1974). Para testar a similaridade entre a composição florítica da comunidade vegetal no estágio original e após a aplicação dos tratamentos, utilizou-se o índice de similaridade de Jaccard. 
A análise de congruência foi aplicada para testar a associação entre os atributos físicos e químicos do solo e a composição florística da vegetação registrada no último levamentamento (terceiro: 25/6/2006) após a aplicação dos tratamentos.

Com a finalidade de identificar possíveis efeitos de manchas de solo com variações nas suas propriedades na área experimental, além dos efeitos dos tratamentos aplicados, sobre os padrões da composição dos levantamentos florísticos, adotaram-se as técnicas de agrupamentos e ordenação. Para tanto, utilizou-se a análise multivariada com transformação dos dados com base na distância de corda e aplicativos MULTIV 2.4.2 (Pillar, 2005a) e SYNCSA 2.2.4 (Pillar, 2005b). Para as análises univariadas (variância e comparação das médias), utilizou-se o aplicativo ASSISTAT, versão 7.4 beta (Silva \& Azevedo, 2006).

\section{Resultados e Discussão}

Na primeira avaliação florística realizada antes da aplicação dos tratamentos (8/1/2005), foram identificadas apenas 38 espécies. Naquela ocasião, a cobertura relativa de E. plana e seu índice de importância eram de 70\% e 44\%, respectivamente (Tabela 1). Esses valores indicam a elevada abundância dessa espécie no acostamento viário estudado e sua agressividade como planta invasora. A segunda espécie mais abundante foi Vernonia nudiflora Less., com cobertura relativa de 4,41\% e índice de importância de 6,74\%. Encontrou-se, naturalmente instalado, Paspalum urvillei Stend., uma das espécies introduzidas, com 0,35\% de cobertura relativa e 1,31\% de índice de importância (Tabela 1).

Na comparação entre o primeiro e o segundo levantamento florístico (27/1/2006) houve aumento da riqueza florística. Essa alteração decorreu das práticas de manejo, que, ao remover parcialmente a vegetação existente, possibilitaram o recrutamento das espécies do banco de sementes do solo (Boccanelli \& Lews, 1994; Medeiros, 2000). No segundo levantamento, registraram-se 60 espécies e, no último, 50 espécies, provavelmente porque o levantamento foi realizado na estação fria, quando as espécies anuais de verão encerram seus ciclos de vida e não são mais visualizadas na comunidade.

No terceiro levantamento florístico (25/6/2006), registrou-se queda substancial na cobertura relativa e no índice de valor de importância do E. plana, de modo que a comunidade vegetal do acostamento viário apresentou nova configuração florística. Essa alteração na estrutura e na composição da comunidade vegetal permitiu que outras espécies ocupassem espaços deixados pelo E. plana e aumentassem seu valor de importância, promovendo acréscimo na riqueza, com reflexos positivos na diversidade, sugerindo aumento do potencial de competição ambiental. Comunidades nesta condição, captando maior quantidade de recursos do meio (Davis et al., 2000) limitam ou impedem os processos de invasão biológica por espécies oportunistas (Naeem et al., 2000). É importante destacar que fatores extrínsecos, especialmente tempo e intensidade de distúrbios (Glenn-Lewin et al., 1992), podem gerar uma covariação positiva (Naeem et al., 2000), como a observada neste estudo, com as espécies nativas $P$. montevidense, $P$. regnelli, Paspalum plicatulum e $P$. urvillei, bem como as espécies introduzidas $M$. maximus, S. sphacelata, e $P$. regnellii, que aumentaram seus valores de cobertura relativa e índice de importância (Tabela 1).

Nas três avaliações da composição florística, foram registradas 86 espécies distribuídas em 29 famílias. Poaceae, Asteraceae, Cyperaceae foram as famílias com maior número de espécies. Schneider \& Irgang (2005) também registram maior número de espécies nessas mesmas famílias. Medeiros et al. (2009) e Carlotto et al. (2010), em levantamentos florísticos realizados em pastagem nativa invadida por E. plana, nas regiões da Campanha e Depressão Central, respectivamente, registraram o maior número de espécies nas famílias Poaceae e Asteraceae. Esses dados, comparados aos obtidos no presente trabalho, indicam que existe uma estrutura mínima e uma composição florística básica semelhante entre eles, representada por alta proporção de espécies das famílias Poaceae e Asteraceae e, secundariamente entre outras como Cyperaceae, Fabaceae, Rubiaceae. A predominância dessas famílias também foi observada por Boldrini (1993) e Focht et al. (2003) em pesquisas realizadas na mesma região ecoclimática deste trabalho.

Entre as 86 espécies registradas neste experimento, 25 eram exóticas destacando-se, além de E. plana, Coniza canadensis (L.) Cronquist, Cyperus rotundus L., Cynodon dactylon (L.) Pers., Lepidium ruderale L., Anagalis minima (L.) E.H.L. Krause, Rumex crispus L., Brachiaria decumbens Stapf. (Tabela 1). Carlotto et al. (2010), trabalhando na mesma região, em área de campo nativo invadida por capim-annoni, registraram a ocorrência de 90 espécies das quais 31 eram ruderais, representando 34\% das espécies residentes no local. A alta frequência de espécies exóticas nos acostamentos viários e nos campos nativos invadidos por E. plana tem alto potencial para contaminar ambientes ainda não invadidos por algumas dessas espécies. Esse fato é preocupante, especialmente em relação à disseminação e expansão de E. plana. 


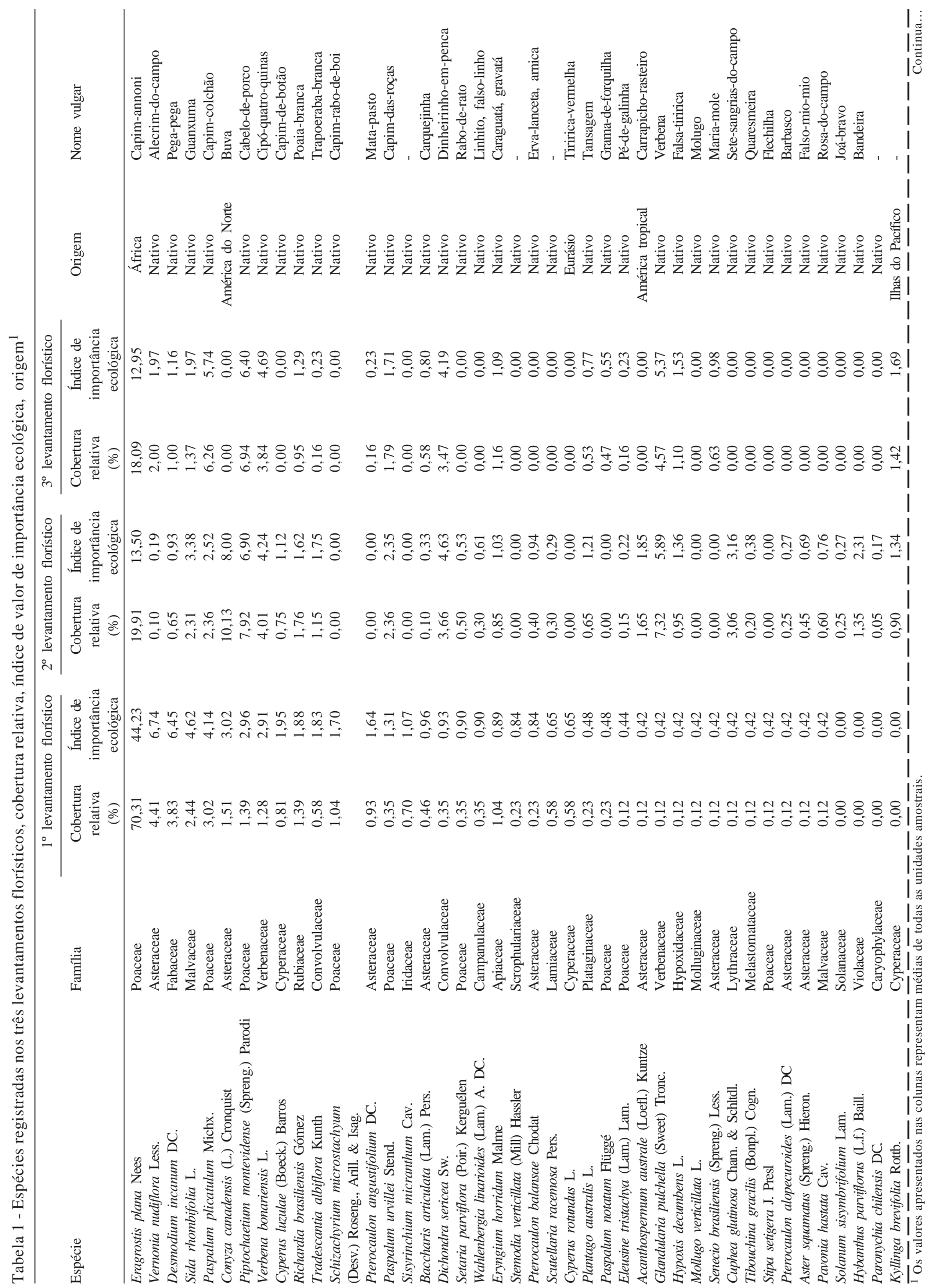




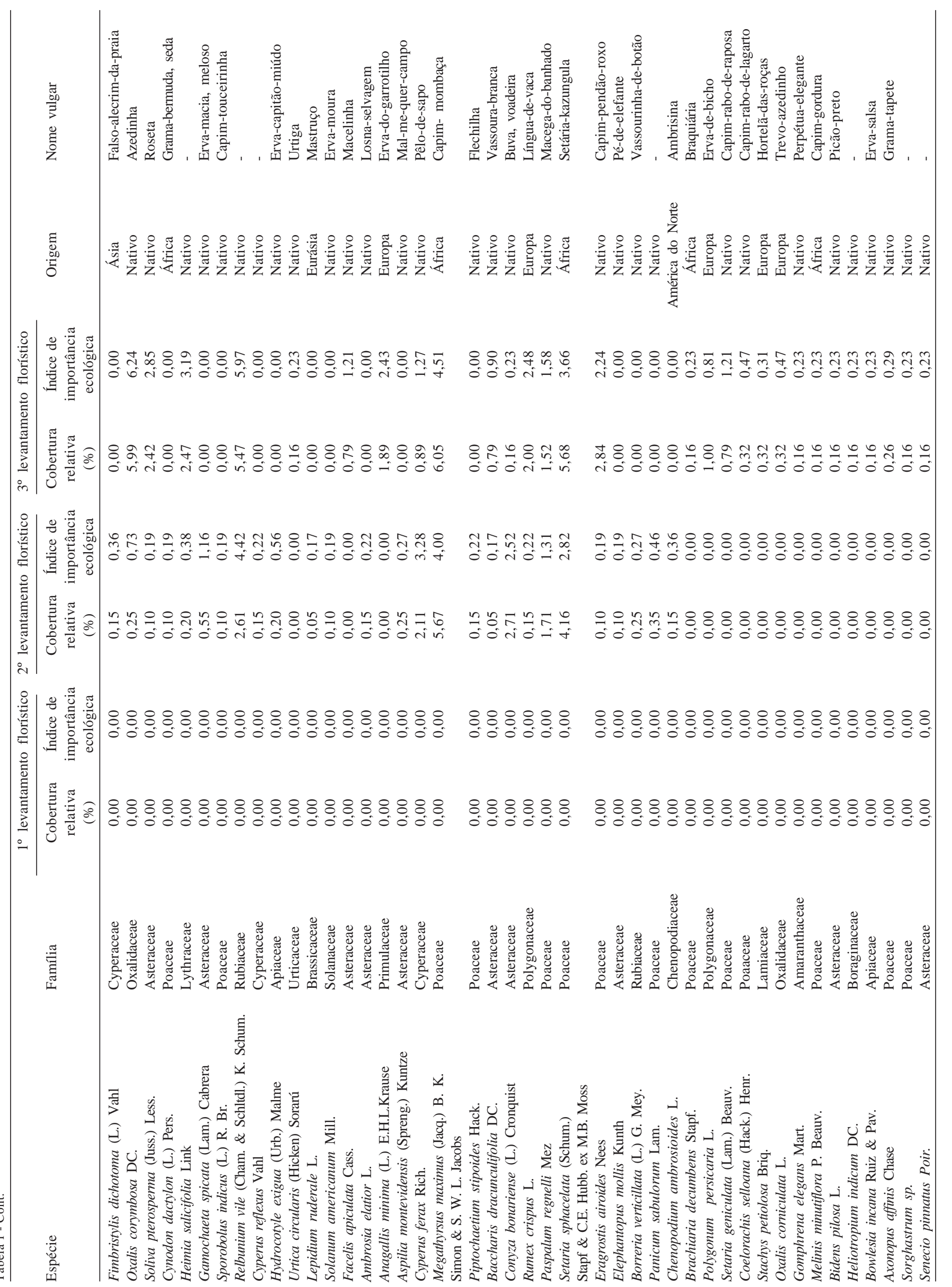


A presença da gramínea nativa Paspalum plicatulum Mitchx. na comunidade vegetal, com alta produção de sementes de elevada viabilidade, pode ser considerada importante em programas de controle do E. plana. No último levantamento, $P$. plicatulum apresentou parâmetros fitossociológicos superiores aos das espécies nativas introduzidas (Paspalum urvillei e Paspalum regnellii) e sua área de cobertura relativa foi ampliada de 3,0\% e índice de importância ecológica de 4,1\% para 6,3\% e 5,7\%, respectivamente. $P$. plicatulum é uma espécie nativa, perene, cespitosa com muitos perfilhos basais com pico de crescimento no verão, coincidindo com E. plana, sendo espontânea nestes ambientes de margens de estradas (Scheffer-Basso \& Gallo, 2008) e sua altura pode atingir até $120 \mathrm{~cm}$. Esta gramínea apresenta resistência ao pisoteio, tolera cortes freqüentes e solos degradados (Batista \& Godoy 1998) além de ser muito resistente a secas prolongadas (Carvalho \& Cruz Filho, 1985). Esse conjunto de características indica que essa espécie apresenta bom valor forrageiro e, ao mesmo tempo, pertence ao grupo das pioneiras e, por isso, seu uso deve ser recomendado em futuros estudos de controle de E. plana.

Entre as espécies nativas de crescimento hibernal, com potencial de competir com E. plana, destacou-se Piptochaetium montevidense (Spreng.) Parodi (Tabela 1). Logo após a aplicação dos tratamentos de subsolagem e gradagem $P$. montevidense teve seu índices cobertura relativa e índice de valor de importância ecológica aumentados, decrescendo em estágios sucessionais posteriores (Tabela 1). Essa característica indica que essa gramínea nativa de ciclo perene e hábito cespitosa faz parte de um conjunto de espécies denominadas iniciais de sucessão (pioneiras). Em geral essas espécies acumulam grande quantidade de sementes no solo. Sabe-se que $P$. montevidense é tolerante a solos secos e degradados, suporta bem o pastejo e surge em áreas de cultivo, margem de estradas e terrenos atingidos por queimadas (Heringer \& Jacques, 2002; Frizzo \& Porto, 2004), por isso, também pode ser uma espécie com potencial para controlar o E. plana.

Neste estudo, espécies da família Asteraceae também apresentaram características de espécies iniciais da sucessão (Gavilanes \& D’ Angieri Filho, 1991; Schneider \& Irgang, 2005) e, por isso, podem contribuir em programas de controle de E. plana.

A presença de espécies pioneiras como $P$. plicatulum e $P$. motevidences é fundamental em vegetações sujeitas a distúrbios frequentes onde avanços e recuos na estrutura e na composição da comunidade se alternam no tempo. Assim, espécies pioneiras nativas não invasoras podem ocupar os eventuais espaços vazios e utilizar os recursos neles disponíveis, evitando que espécies oportunistas invasoras germinem e se estabeleçam como vem ocorrendo com E. plana. O aumento da diversidade florística das margens das rodovias pela manutenção e retorno da flora nativa é essencial para controlar e evitar a invasão biológica. Para isso, as espécies estruturadoras, como as pioneiras nativas ou exóticas não invasoras, promotoras de ambiente para o estabelecimento de espécies de fases serais subsequentes, são importantes para as fases iniciais de um programa de recuperação da composição florística da vegetação viária.

Os índices de similaridade entre as composições florísticas da vegetação dos três levantamentos realizados foram: $1^{\circ}$ versus $2^{\circ}=0,42,1^{\circ}$ versus $3^{\circ}=0,30$ e $2^{\circ}$ versus $3^{\circ}=0,38$. Esses resultados comprovam variação na composição florística na evolução da comunidade partindose do estágio original (antes dos tratamentos) seguindo até o último levantamento. Acredita-se que essa evolução seja consequência do efeito dos tratamentos aplicados. Em razão disso, pode-se inferir que, com o passar do tempo, a comunidade emergente torna-se menos semelhante à comunidade inicial e cessa sua diferenciação quando atinge estabilidade dinâmica do sistema (Pinto-Coelho, 2000).

A análise de agrupamento da composição florística da comunidade do primeiro levantamento em conjunto com o terceiro apresentou cinco grupos nítidos de unidades amostrais que se agregaram em função de características comuns. Os grupos formados (Figura 1) estão assim constituídos: grupo 1 - agregou unidades amostrais menos afetadas pela prática de subsolagem e pela introdução de espécies nativas de Paspalum sp. e exclusão (testemunha). Em razão disso, as composições florísticas foram alteradas em menor intensidade que nas demais unidades. Essas unidades, em comparação às demais, apresentaram maior frequiência de E. plana e de algumas espécies que já se encontravam na comunidade do acostamento. É possível que efeitos alelopáticos negativos do E. plana tenham prejudicado o estabelecimento das três espécies de Paspalum spp. introduzidas (Ferreira et al., 2008), uma vez que a taxa de germinação das sementes foi alta; grupo 2 agregou as unidades amostrais onde se situava $M$. maximus . Nesse caso o efeito da espécie foi superior ao do manejo do solo; grupo 3 - mais uma vez nota-se a semelhança da “exclusão" com a mistura de espécies do gênero Paspalum, além de uma unidade amostral de $S$. sphacelata com baixa taxa de estabelecimento. Houve, em menor grau, a influência do manejo de solo com subsolagem mais gradeação, que apareceu em quatro das seis unidades amostrais constituintes deste grupo; grupo 3 - formado por duas 


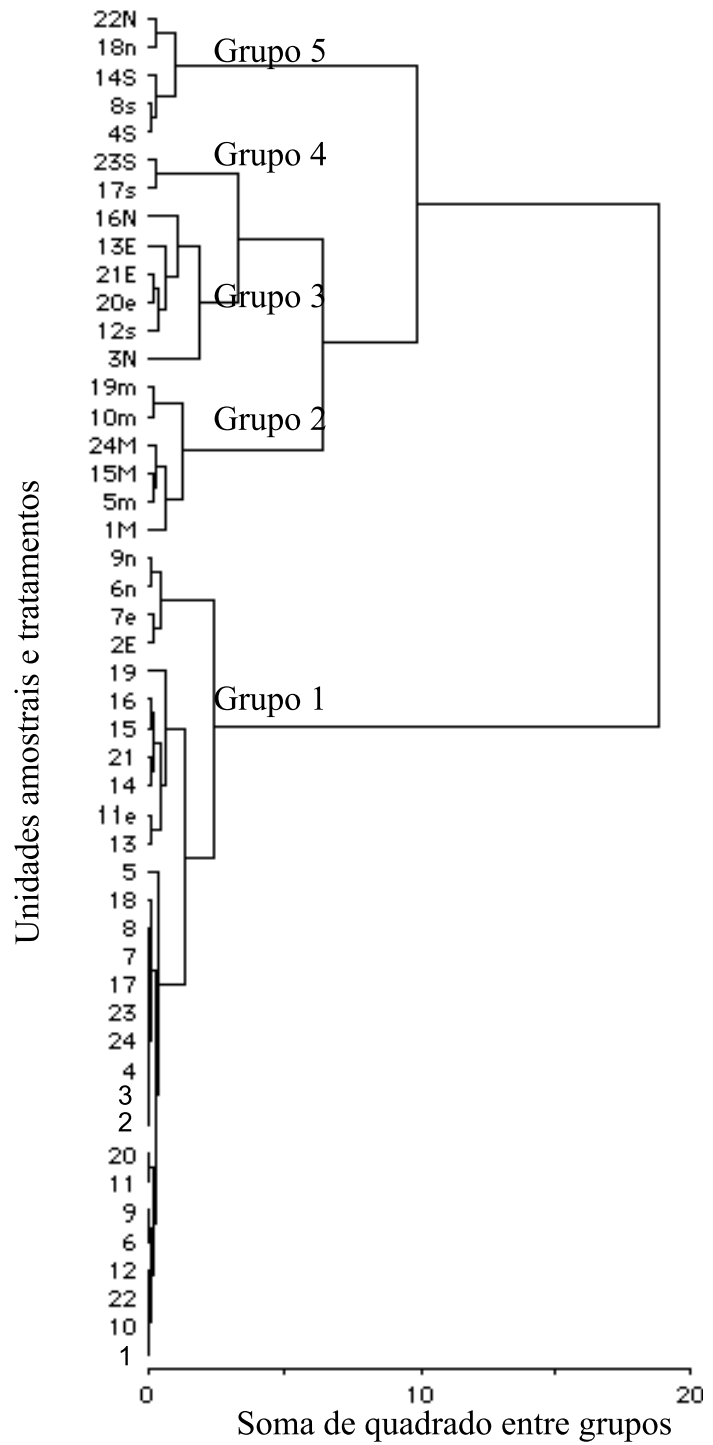

As letras maiúscula $\mathrm{M}, \mathrm{E}, \mathrm{N}$ e $\mathrm{S}$ representam o tratamento de subsolagem + gradeação e adubação. As letras minúsculas m, e, n e s representam o tratamento subsolagem. Independentemente de ser caixa alta ou baixa, as letras representam as espécies $\mathrm{m}=$ Megathyrsus maximus; e = exclusão; $\mathrm{n}$ = mistura de Paspalum spp; e s = Setaria sphacelata. Os números isolados representam situação no primeiro levantamento florístico.

Margem viária, Fazenda São Lucas, Rio Pardo, Rio Grande dos Sul, 2006.

Figura 1 - Dendrograma da análise de agrupamento das 24 unidades amostrais obtido dos dados da primeira e terceira florística, pelo método da soma de quadrado (variância mínima).

unidades amostrais onde $S$. sphacelata melhor se estabeleceu e seu efeito sobrepujou os efeitos do manejo de solo; grupo 5 - caracterizou-se pela união de unidades amostrais com S. sphacelata e mistura de Paspalum spp. com baixo estabelecimento, porém diferenciou-se da exclusão quanto à cobertura florística. O efeito de tratamento de solo teve pouca influência na formação desse grupo. O fato das seis subparcelas com $S$. sphacelata não estarem todas no grupo 5 pode ser atribuído às variações nas propriedades do solo visualizadas em algumas unidades amostrais por ocasião do estabelecimento do experimento.

Para melhor compreender as relações entre os tratamentos, efetuou-se uma análise de ordenação dos dados referentes ao levantamentos florísticos um e três obtendo-se um diagrama de dispersão das unidades amostrais (Figura 2). O diagrama mostra a existência de cinco grupos nítidos de unidades amostrais, dispostos segundo os tratamentos de solo e espécies introduzidas (cobertura). Esse arranjo em cinco grupos assemelha-se aos grupos formados no dendograma; seus padrões são revelados pela distribuição no espaço multivariável e suas relações com os fatores externos resumidos em dois eixos principais que respondem por $52,7 \%$ das variações ocorridas nas unidades amostrais, sendo o eixo 1 de $37,4 \%$ e o eixo 2 de 15,3\%. A partir da ordenação do eixo 1, visualiza-se o redirecionamente da successão de uma situação de vegetação campestre dominada por E. plana, agregando todas as unidades amostrais que se comportaram

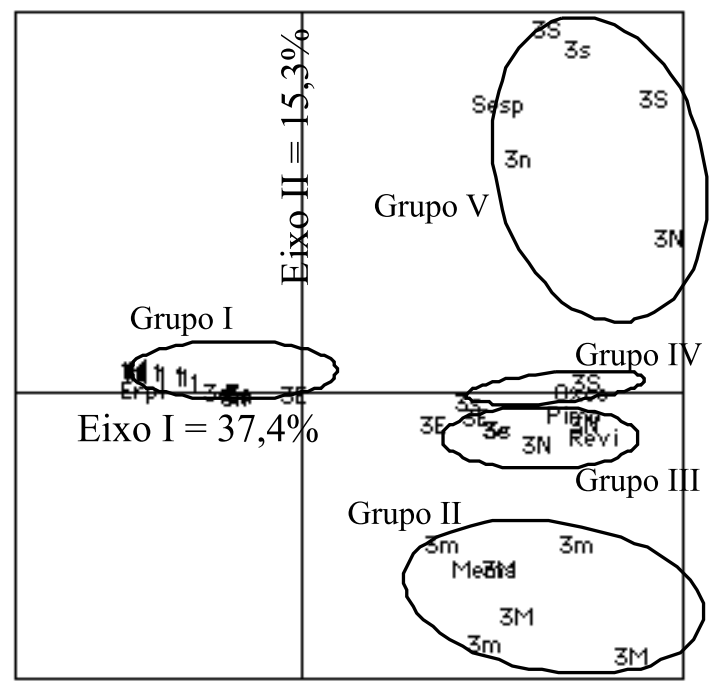

Os padrões são revelados pela distribuição no espaço multivariável e suas relações com os fatores externos resumidos em dois eixos principais (I e II) que explicam 52,7\% da variação ocorridas nos levantamentos florísticos, demonstrando a ordenação dos cinco grupos formados. Quanto ao tratamento do solo, as letras maiúsculas (M, E, N, S) representam o tratamento subsolagem mais gradagem e adubação. As letras minúsculas (m, e, n, s) representam o tratamento subsolagem. Quanto à cobertura, independentemente de ser caixa alta ou baixa, $\mathrm{m}=$ Megathyrsus maximus, e = exclusão, $\mathrm{n}=$ mistura de Paspalum spp, $\mathrm{s}=$ Setaria sphacelata. Espécies com maiores coeficientes de correlação com o eixo I: E. plana = erpl $(-0,99) ;$ Relbunium vile $=$ revi $(0,76) ;$ Oxalis corimbosa $=$ oxco $(0,71)$; Piptochaetium montevidense $=$ pimo $(0,69)$ e M. maximus $=$ mema $(0,55)$ No segundo eixo tem-se: $S$. sphacelata $=\operatorname{sesp}(0,79)$ e $M$. maximus $(-0,69)$. Margem viária, Fazenda São Lucas, Rio Pardo, Rio Grande do Sul, 2006.

Figura 2 - Diagrama de dispersão com correlações maiores que 0,6 , obtidos por análise de coordenadas principais com base em distância de corda, com os dados do primeiro e do terceiro levantamentos florísticos, das 24 unidades amostrais. 
de forma semelhante ao estágio inicial, para nova configuração florística a partir da aplicação dos tratamentos. Bugg et al. (1997), em estudo de restauração de vegetação em margens de rodovias na Califórnia visando avaliar o potencial de aproveitamento de espécies introduzidas nessas comunidades para uso em programa de manejo, concluíram que os acessos de gramíneas perenes introduzidos que conservaram no mínimo $25 \%$ de cobertura do dossel eram desejáveis para o uso em projetos de recuperação da cobertura florística local. Esses autores demonstraram a possibilidade de reestruturar a vegetação natural por meio da reeintrodução de espécies nativas e, desse modo, restituir sua capacidade de evitar a invasão. Neste trabalho comprovou-se a possibilidade de reestruturar a vegetação natural invadida pelo E. plana por meio da introdução de espécies de gramíneas e da exclusão associadas a distúrbios do solo.

$\mathrm{Na}$ análise de ordenação, as espécies com maiores coeficientes de correlação com o eixo 1 foram: E. plana $(-0,99)$, indicando forte correlação com a comunidade original onde era a espécie predominante; Relbunium vile $(0,76)$; Oxalis corimbosa $(0,71)$; P. montevidense $(0,69) \mathrm{e}$ $M$. maximus $(0,55)$. No segundo eixo, tem-se: $S$. sphacelata $(0,79)$ e $M$. maximus $(-0,69)$.

O nível de congruência ou correlação matricial entre o terceiro levantamento florístico e os atributos de solo (Figura 3) comprovou que as mais altas correlações e a capacidade de troca de cátions efetiva $(0,18)$, cálcio $(0,17)$, fósforo $(0,17)$, cobre $(0,17)$, magnésio $(0,16)$ apresentaram valores baixos, indicando que as variáveis do solo pouco explicaram as variações ocorridas nas análises florísticas (baixa correlação). Outros fatores foram mais determinantes para essa variação, como os tratamentos de preparo de solo e a concorrência das espécies introduzidas na comunidade.

A análise de variância revelou significância para o efeito da interação entre os tratamentos de preparo do solo

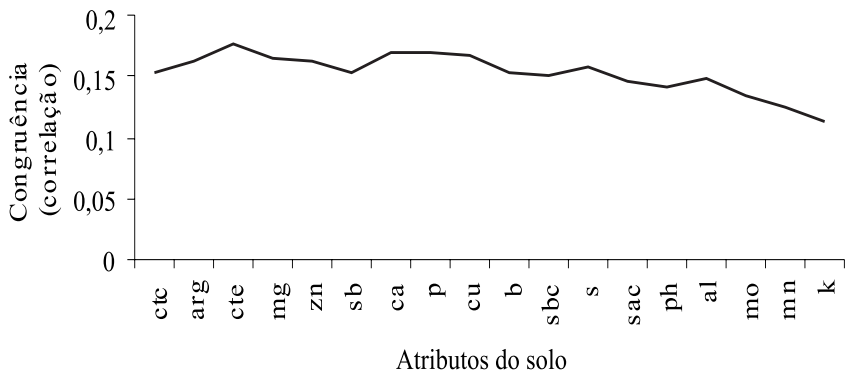

Sendo cumulativamente da esquerda para a direita, ctc (capacidade de troca de cátions), arg (argila), cte (capacidade de troca de cátions efetiva), mg (magnésio), zn (zinco), sb (soma de bases trocáveis), ca (cálcio), p (fósforo), cu (cobre), b (boro), sbc (soma de base da ctc), s (enxofre), sac (saturação do alumínio da ctc efetiva), al (alumínio trocável), mo (molibdênio), mn (manganês), k (potássio) Margem viária, Fazenda São Lucas, Rio Pardo, Rio Grande do Sul, 2006.

Figura 3 - Perfil de congruência máxima entre o último levantamento florístico, em junho de 2006, e os atributos de solo.

e introdução de espécies sobre a cobertura de E. plana (Tabela 2). Na comparação das médias registrou-se diferença estatística da mistura de Paspalum spp. dentro de tratamento de solo, indicando que a subsolagem mais gradeação foi mais eficiente em reduzir a cobertura do E. plana que a subsolagem simples. Com maior revolvimento maior do solo (subsolagem mais gradeação), volume maior de sementes pode ter sido posto em camadas profundas, impedindo sua germinação (Medeiros et al., 2006), que teve reflexo direto na diminuição do número de plantas e na cobertura pelas mesmas. As comparações interespecíficas, dentro de preparo de solo, subsolagem seguido de gradeação mais adubação, mostraram significância entre $S$. sphacelata e exclusão, bem como entre exclusão e mistura de Paspalum spp. Entretanto, quando se analisou o efeito da subsolagem, verificou-se significância entre $S$. sphacelata e exclusão e S. sphacelata e nativas, demonstrando dessa forma que o preparo de solo teve forte influência na redução da cobertura do E. plana na área estudada.

Tabela 2 - Cobertura de Eragrostis plana (índice de Van der Maarel) em função de tratamentos de solo e espécies introduzidas em margem de rodovia

\begin{tabular}{|c|c|c|c|c|c|}
\hline \multirow[b]{2}{*}{ Tratamentosde solo } & \multicolumn{4}{|c|}{ Espécie } & \multirow[b]{2}{*}{ Médias } \\
\hline & Megathirsus maximus & Setaria sphacelata & Mistura de Paspalum spp. & Exclusão & \\
\hline Subsolagem + gradeação & $3,67 a \mathrm{AB}$ & $2,00 \mathrm{aB}$ & $2,45 b B$ & $6,67 \mathrm{aA}$ & 3,70 \\
\hline Subsolagem & $4,67 \mathrm{aAB}$ & $3,89 \mathrm{aB}$ & $7,56 \mathrm{aA}$ & $7,33 \mathrm{aA}$ & 5,86 \\
\hline
\end{tabular}

Médias seguidas de letras minúsculas nas colunas e letras maiúsculas nas linhas não diferem estatisticamente pelo teste Tukey a 5\% de probabilidade.

\section{Conclusões}

O índice de similaridade varia entre a composição florística da vegetação inicial e a da florística emergente. As gramíneas nativas Paspalum plicatulum, de ciclo estival, e Piptochaetium montevidense, de ciclo invernal, e nativa introduzida Paspalum urvillei são epécies que podem contribuir para o controle do E. plana nos 
acostamentos viários. Os melhores índices de controle de E. plana são obtidos por meio da introdução das gramíneas cultivadas $M$. maximus e $S$. sphacelata associados a subsolagem mais gradeação e adubação. A prática da exclusão mostrou potencial no controle de capim-annoni.É necessário dar continuidade a estudos que avaliem o potencial de outras espécies de gramíneas e de outras práticas de manejo do solo com a finalidade de colocar à disposição dos produtores, instituições públicas e privadas mais alternativas de controle de focos dispersores de Eragrostis plana dos acostamentos da malha viária do Rio Grande do Sul.

\section{Agradecimentos}

À Fazenda São Lucas, município de Rio Pardo, pela gentileza de ceder as estruturas de sua propriedade; à Prefeitura de Rio Pardo, por apoiar a execução do experimento num acostamento viário de uma estrada municipal; e ao Sindicato Rural de Rio Pardo; ao CNPq e à CAPES, pelo apoio Financeiro.

\section{Referências}

BATISTA, L.A.R.; GODOY, R. Capacidade de produção de sementes em acessos do gênero Paspalum. Revista Brasileira de Zootecnia, v.27, n.5, p.841-847, 1998.

BOCCANELLI, S.I.; LEWS, J.P. The seed bank of an old pampean prairie and its relation with the standing vegetation, Pesquisa Agropecuária Brasileira, v.29, n.12, p.1883-1840, 1994.

BOLDRINI, I.I. Dinâmica de vegetação de uma pastagem natural sob diferentes níveis de oferta de forragem e tipos de solo, Depressão Central do Rio Grande do Sul. 1993. 262f. Tese (Doutorado em Zootecnia) - Universidade Federal do Rio Grande do Sul, Porto Alegre.

BOLDRINI, I.I. Campos do Rio Grande do Sul: caracterização fisionômica e problemática ocupacional. Boletim do Instituto de Biociências, n.56, p.1-39, 1997.

BRAUN-BLANQUET, J. Fitossociología: bases para el estudio de las comunidades vegetales. 3.ed. Madrid: Blume, 1979. 820p.

BUGG, R.L.; BROWN, C.S.; ANDERSON, J.H. Restoring native perennial grasses to rural roadsides in the Sacramento Valley of California establishment and evaluation. Restoration Ecology, v.5, n.3, 214-228, 1997.

CARLOTTO, S.B.; MEDEIROS, R.B.; PELlEGRINI, C.B. et al. Comportamento ingestivo diurno de vacas primíparas em pastagem nativa dominada por capim-annoni-2 com suplementação protica e mineral em diversas estações climáticas, Revista Brasileira de Zootecnia, v.39, n.3, p.454-461, 2010.

CARVALHO, M.M.; CRUZ FILHO, A.B. Estabelecimento de pastagem. Coronel Pacheco: EMBRAPA CNPGL, 1985. 46p. (Circular técnica, 26).

DAVIS, M.A.; GRIME, J.P.; THOMPSON, K. Fluctuating resources in plant communities: a general theory of invasibility. Journal of Ecology, v.88, p.528-534, 2000.

FERREIRA, N.R.; MEDEIROS, R.B.; SOARES, G.L.G. Potencial alelopático do capim-annoni-2 (Eragrostis plana Nees) na germinação de sementes de gramíneas perenes estivais. Revista Brasileira de Sementes, v.30, n.2, p.43-53, 2008.

FOCHT, T.; PILLAR, V.D. Spatial patterns and relations with site factors in a campos grassland under grazing. Brazilian Journal of Biology, v.63, n.3, p.423-436, 2003.
FORMAN, R.T.T.; SPERLING, D.; BISSONETTE, J.A. et al. Road ecology - science and solutions. Washington: Island Press, 2002. 467p.

FRIZZO, T.C.E.; PORTO, M.L. Zoneamento da vegetação e sua relação com a ocorrência de estruturas mineralizadoras na mina Volta Grande, Lavras do Sul, RS, Brasil. Iheringia Série Botânica, v.59, n.1, p.5-12, 2004.

GAVILANES, M.L.; D’ANGIERI FILHO, C.N. Flórula ruderal da cidade de Lavras, MG. Acta Botânica Brasílica, v.5, n.2, p.77-88, 1991.

GLENN-LEWIN, D.C.; PEET, R.K.; VEBLEN, T.T. Plant succession: theory and prediction. London: Chapman \& Hall, 1992. 368p.

HERINGER, I.; JACQUES, A.V.A. Composição florística de uma pastagem natural submetida a queima e manejos alternativos. Ciência Rural, v.23, n.2, p.315-321, 2002.

IRGANG, B.E. Flora ilustrada do Rio Grande do Sul. Umbelliferae II. Gênero Eryngium L. Boletim do Instituto Central de Biociências, n.32, p.1-86, 1974.

LISBOA, C.A.V.; MEDEIROS, R.B.M.; AZEVEDO, E.B. et al. Poder germinativo de sementes de capim-annoni-2 (Eragrostis plana Ness) recuperadas em fezes de bovinos. Revista Brasileira de Zootecnia, v.38, n.3, p.405-410, 2009.

MARODIN, S.M.; BAPTISTA, L.R.M. Plantas utilizadas como medicinais no município de Dom Pedro de Alcântara, Rio Grande do Sul, Brasil. 1. Origem e aspectos ecológicos. Iheringia Série Botânica, v.56, p.131-146, 2001.

MEDEIROS, R.B. Bancos de sementes no solo e dinâmica vegetacional. In: REUNIÃO DO GRUPO TÉCNICO EM FORRAGEIRAS DO CONE SUL - ZONA CAMPOS, 18., 2000, Guarapuava. Anais... Guarapuava: Comissão Paranaense de Avaliação de Forrageiras, 2000. p.62-87.

MEDEIROS, R.B.; PILLAR, V.P.; REIS, J.C.L. Expansão de Eragrostis plana Ness. (capim-annoni-2) no Rio Grande do Sul e indicativos de controle. IN: MEMORIAS DE LA REUNIÓN DEL GRUPO TÉCNICO REGIONAL DEL CONO SUR EM MEJORAMIENTO Y UTYILIZACIÓN DE LOS RECURSOS FORRAJEROS DEL ÁREA TROPICAL E SUBTROPICAL, GRUPO CAMPOS, 20., 2004, Salto. Anais... Salto: Regional Norte de la Universidad de la República, 2004. p.208-211.

MEDEIROS, R.B.; FOCHT, T. Invasão, prevenção, controle e utilização do capim-annoni-2 (Eragrostis Plana Ness) no Rio Grande do Sul. Pesquisa Agropecuária Gaúcha, v.13, n.1-2, p.105-114, 2007.

MEDEIROS, R.B.; FOCHT, T.; FREITAS, M.R. et al. Longevidade de sementes de E. plana enterradas em solo de campo natural. IN: REUNIÃO TÉCNICA DO GRUPO TÉCNICO EM FORRAGEIRAS DO CONE SUL - ZONA CAMPOS, 21., 2006. Pelotas Anais... Pelotas: Embrapa Clima Temperado [2006] (CD-ROM).

MEDEIROS, R.B.; SAIBRO, J.C.; FOCHT, T. Invasão de capimannoni (Eragrostis plana Nees) no Bioma Pampa do Rio Grande do Sul In: ____ Campos Sulinos - conservação e uso sustentável da biodiversidade. Brasília: UFRGS, 2009. p.319-332.

Moreno, J.A. Clima do Rio Grande do Sul. Porto Alegre: Secretaria de Agricultura. 1961. 41p.

MUELLER-DOMBOIS, D.; ELLENBERG, H. Aims and methods of vegetation ecology. New York: John Wiley, 1974. 547p.

NAEEM, S.; KNPOS, J.M.H.; TILMAN, D. et al. Plant diversity increases resistance to invasion in the absence of covarying extrinsic factors. Oikos, v.91, p.97-108, 2000.

PILLAR, V.D.P. MULTIV: aplicativo para análise multivariada e teste de hipótese - versão 2.4.2. Porto Alegre: Departamento de Ecologia da Universidade Federal do Rio Grande do Sul, 2005a.

PILLAR, V.D.P. SYNCSA: software integrado para análise multivariada de comunidades baseada em caracteres, dados de ambiente, avaliação e testes de hipóteses - versão 2.2.4. Porto Alegre: Departamento de Ecologia Universidade Federal do Rio Grande do Sul, 2005b. 
PINTO-COELHO, R.M. Fundamentos em ecologia. Porto Alegre: Artes Medicas Sul, 2000. 252p.

REIS, J.C.L. Capim annoni-2: Origem, morfologia, características, disseminação In: REUNIÃO REGIONAL DE AVALIAÇÃO DE PESQUISA COM ANNONI-2, 1991, Bagé. Anais... Bagé: EMBRAPA-CPPSUL, 1993. p.5-23. (Documento, 7).

REIS, J.C.L.; COELHO, R.W. Controle do capim-annoni-2 em campos naturais e pastagens. Pelotas: Embrapa Clima Temperado, 2000. p.21. (Circular Técnica, 22).

SCHEFFER-BASSO, S.M.; GALLO, M.M. Aspectos morfológicos e bromatológicos de Paspalum plicatulum. Revista Brasileira de Zootecnia, v.37, n.10, p.1758-1762, 2008.

SCHNEIDER, A.A.; IRGANG, B.E. Florística e fitossociologia de vegetação viária no município de Não-Me-Toque, Rio Grande do Sul, Brasil. Iheringia Série Botânica, v.60, n.1, p.49-62, 2005.

SILVA, F.A.S.; AZEVEDO, C.A.V. A new version of the assistat statistical assistance software. In: WORLD CONGRESS ON COMPUTERS IN AGRICUlTURE, 4., 2006, Orlando. Anais.. Orlando: American Society of Agricultural Engineers, 2006. p.393-396.

STRECK, E.V.; KÄMPF, N.; DALMOLIN, R.S.D. et al. Solos do Rio Grande do Sul. Porto Alegre: MATER/RS; UFRGS, 2002. 126p.

TIVY, J. Biogeography: a study of plants in the ecosphere. 3.ed. Harlow: Longman, 1993. 462p.

VAN DER MAAREL, E. Transformation of cover-abundance values in phytosociology and its effects on community similarity. Vegetatio, v.2, n.39, p.97-114, 1979. 